\title{
Coverage and usage of insecticide treated nets (ITNs) within households: associated factors and effect on the prevalance of malaria parasitemia in the Mount Cameroon area
}

\author{
Charles Njumkeng ${ }^{1,3^{*}}$ D, Tobias O. Apinjoh ${ }^{2}$, Judith K. Anchang-Kimbi ${ }^{4}$, Elvis T. Amin ${ }^{1}$, Elvis A. Tanue ${ }^{1,5}$, \\ Clarisse Njua-Yafi ${ }^{6,7}$ and Eric A. Achidi ${ }^{2}$
}

\begin{abstract}
Background: Insecticide-treated nets (ITNs) are a widely used tool that has been proven to be effective in the prevention and control of malaria in malaria endemic countries. However, usage varies among households and can greatly affect the benefits of ITNs as a control tool for malaria transmission. This study determined the coverage and usage of ITNS as well as associated factors and the effect of coverage and usage on the prevalence of malaria parasitemia within households in the Mount Cameroon area.

Methods: A cross-sectional survey was conducted between August and September 2014 in six communities within the Mount Cameroon area. Households within the communities were enrolled through multistage sampling and household survey was done using a structured questionnaire. Capillary blood was collected for malaria parasite determination. Data was analysed using SPSS version 20 for windows. Differences in proportions were assessed using the Chi-square test while factors affecting ITNs usage were assessed in multivariate logistic regression at a statistical significance of $P \leq 0.05$.
\end{abstract}

Results: A total of 504 households were surveyed, 1564 bed spaces reported while 915(58.5, 95\% Cl: 56.1-60.9) of the bed spaces had nets and $391(77.6,95 \% \mathrm{Cl}, 74.0-80.2)$ of the households had at least one bed net. The odds of using ITNs was 2 folds higher $(\mathrm{OR}=2.41 ; 95 \% \mathrm{Cl} 1.58-3.69 p=0.001)$ and 3 folds higher $(\mathrm{OR}=3.149,95 \% \mathrm{Cl} 1.53-6.47 p=$ 0.002) among houses with 5 to 9 occupants and above 10 occupants respectively when compared to houses with less than 5 occupants. In addition, Individuals living in cement block houses were less likely to use ITNs.

Compared to those living in wooden houses ( $\mathrm{OR}=0.488,95 \% \mathrm{Cl}: 0.269-0.885 ; \mathrm{p}=0.018)$. Rural communities had lower ITN coverage compared to semi-urban communities $(p=0.0001)$. Increase in ITNs coverage significantly reduces malaria prevalence (correlation $-0.899, p=0.015$ ).

Conclusion: Despite the efforts made to scale up ITN distribution so that universal coverage can be attained, coverage remains low. Increasing coverage and putting in place a mechanism to replace torn nets will go a long way reduce the prevalence of malaria parasitemia.

Keywords: Coverage, Usage, ITNS, Households, Malaria, Cameroon

\footnotetext{
* Correspondence: njumkengcharles@yahoo.com

${ }^{1}$ Global Research Education and health Foundation Buea, Molyko, P.O. BOX

356, Buea, South West Region, Cameroon

${ }^{3}$ Department of Microbiology and Parasitology, University of Buea, Buea,

Cameroon

Full list of author information is available at the end of the article
}

(c) The Author(s). 2019 Open Access This article is distributed under the terms of the Creative Commons Attribution 4.0 International License (http://creativecommons.org/licenses/by/4.0/), which permits unrestricted use, distribution, and reproduction in any medium, provided you give appropriate credit to the original author(s) and the source, provide a link to the Creative Commons license, and indicate if changes were made. The Creative Commons Public Domain Dedication waiver (http://creativecommons.org/publicdomain/zero/1.0/) applies to the data made available in this article, unless otherwise stated. 


\section{Background}

Malaria is one of the major public health problems with estimated 212 million malaria cases and 429, 000 malaria related death across the globe in 2016. In Africa, access to the tools needed for the prevention and treatment of malaria is still limited to millions of people in need [1]. In Cameroon, the Ministry of Public Health through the National Malaria Control Program (NMCP) has put in place a number of strategies to fight this disease. This includes insecticide treated nets (ITNS), free treatment of uncomplicated malaria for children below 5 years of age using Artemisinin-based combination therapies (ACTs), and prompt management of confirmed cases with Artemisinin-based Combination Therapy, intermittent preventive treatment with sulphadoxinepyrimethamine for pregnant women, environmental hygiene and in-door residual spraying [2]. From 2002 the Cameroon government has conducted many campaigns for the free distribution of ordinary ITNs and long lasting insecticides treated ITNs all over the country [3]. According to the Ministry of Public Health about two million ITNs were distributed between 2005 and 2008, over eight million distributed in 2011 and about twelve million in 2015 as a strategy to significantly reduce the morbidity and mortality burden of malaria in the country [6].

Despite the government's effort to scale up ITN distribution in Cameroon, full coverage and proper usage may be limited due to the lack of consistent distribution and other issues related to maintenance and replacement of nets, as well as local beliefs and poor understanding of the relationship between mosquitoes and malaria at the community level [4-6]. In addition, studies have observed great disparities between ownership versus usage of ITNs [3, 7-11].

To acquire the anticipated benefits of ITNs, they should be properly and consistently used within households rather than merely owning them. WHO recommends that periodic household surveys should be done to determine whether the populations at risk have sufficient ITNs and whether they are using them properly [12]. Community and household factors such as discomfort, belief of low mosquito density, inconvenience installing the nets, residence, educational background, age and gender differences are among the frequently reported reasons for not using the acquired ITNs $[3,6,13,14]$.

In a previous publication [5] it was demonstrated that ITN usage reduces the prevalence of malaria parasitemia which is considered as a measure of malaria burden. However, this publication did not include an analysis of community and household specific factors affecting coverage and proper usage of ITNs. This study used an unbiased approach to analyse and identify factors affecting ITN usage at household and community levels so that they can be addressed to reduce malaria transmission.

\section{Methods}

\section{Ethical considerations}

Ethical approval for the study was obtained from the Institutional Review Board of the Faculty of Health Sciences, University of Buea ( $\mathrm{N}^{0}$ : 2014-02-0191). Administrative authorization was obtained from the South West Regional Delegation of Public Health and from the District Medical Officer of Tiko and Buea. Written informed consent was obtained from participants after the purpose of the study and the role of the participants was well explained verbally and in the consent form.

\section{Study area}

The study was carried out in six major settlements (Ombe, Mutengene, Dibanda, Bolifamba, Muea and Tole) selected along the eastern slope of Mt Cameroon with different malaria transmission profiles and geographic features $[3,15]$. Ombe and Tole are rural communities while Mutengene, Dibanda, Bolifamba and Muea are semi-urban communities. The communities included in this study are characterized by small bushes and stagnant water (during the raining seasons) that favors anopheles breeding throughout the year [16]. The population of this area is comprised of many ethnic groups, majority coming from neighboring regions in search of its fertile volcanic land for farming and business opportunities. This area has two main house types, namely the cement brick and wooden houses [5, 16-18].

The area has moved from a Malaria hyper endemic area to a meso-endemic area, with maximum transmission occurring during the rainy seasons and at lower altitude [19, 20]. Majority of the malaria infections in this area are cause by the $P$. falciparum while Anopheles gambiae has been identified as the dominant and most important malaria vector in the area $[5,19,21] A$. gambiae annual biting rate is estimated as 287 infective bites per person while daily the overall Entomological Inoculation Rates (EIR) is estimated to be 3.93 infective bites per person $[5,22]$.

\section{Study design and sampling technique}

This study was a cross-sectional household survey which was conducted between August and September 2014. The communities were randomly selected along eastern the slop of Mount Cameroon based on altitude which is an indicator of malaria transmission [5]. Within each selected community, a household was selected at random as a starting point and the rest selected after every five households (Systematic sampling technique). The number of households to skip before enrolling one (five households) was calculated by dividing the total number of households in the community by the number of households required for the study.

Structured questionnaires (Additional file 1) were then administered to heads of households (with priority given to mothers) and when faced with a situation where the 
head of the household was absent, any adult within the household able of providing reliable information was interviewed. Pidgin English was used to administer the questionnaires. All reported ITNs were inspected except in some cases where inspection was not possible (one of the rooms is locked and the key is not readily available). Community health workers were trained to administer the questionnaires and they were supervised during the exercise. Before the survey, the questionnaire was tested in a non-survey population to ensure validity of the precoded answers. Capillary blood samples were collected from individuals living within the selected communities for malaria parasite examination. The community members were sensitized prior to each sample collection visit.

\section{Malaria Parasitemia examination}

After cleaning the lobe of a finger with cotton wool soaked in $70 \%$ ethanol, the finger was pricked using a sterile lancet. Two freefall drops of blood were collected from the finger pricked and used to prepare thick and thin blood films on labeled slides and then air dried. The thin films were fixed with methanol and both films were stained with $10 \%$ Giemsa (Sigma, St. Lothanoluis, USA) for $15 \mathrm{~min}$. The malaria parasitaemia status and density were determined under oil immersion with the $100 \mathrm{x}$ objective, of a binocular Olympus microscope (Olympus Optical Co., Ltd., Japan) while the Plasmodium species were identified on the thin blood smear. A smear was only considered negative if no malaria parasites were seen in 50 high power fields [23].

\section{Sample size determination}

The sample size of the study population was calculated using the formula below [24]:

$$
\mathrm{n}=\frac{\left\{\frac{\mathrm{P}(1-\mathrm{P})}{\frac{\mathrm{A}^{2}}{Z^{2}}+\frac{\mathrm{P}(1-\mathrm{P})}{N}}\right\}}{\mathrm{R}}
$$

Where: $n=$ sample size required,

$\mathrm{N}=$ number of household in the community $=14,897$ (sum of households in Mutengene, Ombe Bolifamba Muea and Tole),

$\mathrm{P}=$ estimated variance in population, as a decimal: (0.3 for 70-30), $\mathrm{A}=$ Precision desired, expressed as a decimal (i.e.0.05 for 5\%), $\mathrm{Z}$ is based on confidence level: 1.96 for 95\% confidence and $\mathrm{R}=$ Estimated net coverage, as a decimal (59.7\%) [3].

A minimum of 451 households were required for the study. The number of households selected per community was calculated as a proportion of the sum of all the households.

\section{Definition of terms}

A household was considered to be a home with a head, his / her dependents or spouse and who feed from the same kitchen and sleep under the same roof. Any long lasting insecticide treated net or a conventional ITN which was treated not more than 3 years ago was consider as ITN [5]. "Bed space" was defined as any space or any facility that is regularly used for sleeping or intended to be used for sleeping by someone.

ITN ownership was defined as being in possession of an insecticide treated bed net. The net could be in use or not in use but must be in a good state. Any net that had not been used even once since it was obtained, was termed net in package.

Regular users of ITNs were defined as those who slept under an ITN for at least the last two nights before the survey was conducted. An irregular user was defined as someone who had an ITN hung over his/her bed but reported that he/she did not sleep under the ITN for 1 or 2 days before the survey. Non users were defined as those who did not use ITNs at all. Any ITN that was found hung over a sleeping space was considered to be a net in use.

\section{Determination of ITN ownership and usage}

The proportions of ITN ownership, usage and coverage were calculated respectively as follows:

ITNownership $=\frac{\text { Number of households with at least an ITN }}{\text { Total number of households surveyed }}$

ITNin use $=\frac{\text { Number of nets found hung over a sleeping space }}{\text { Total number of nets reported and confirmed }}$

ITN usage rate $=\frac{\text { Number of households that used at least one ITN the previous night }}{\text { Total number of households with at least one ITN }}$

ITNcoverage $=\frac{\text { Total number of ITNsreported }}{\text { Total number of sleeping spaces reported }}$

Data management and statistical analysis

Data obtained from each participant was entered into the research log books and checked by the lead author. The data were then entered into Epi info version 7.0 software. Any discrepancy in field records was verified using the original questionnaires. After data cleaning, analysis was done using SPSS Statistics 20.0 Statistical software for windows (SPSS Inc., Chicago USA). ITN coverage per household was expressed as means \pm SD. The comparison between ITN coverage, ownership, usage and the nature of nets between different study sites was assessed using the Chi-square test. The association between net usage and factors affecting its use was done using bivariate logistic regression and adjusted using multivariate logistic regression. A bivariate logistic regression was also used to determine the relationship between ITN usage and the prevalence of malaria. Pearson correlation 
was used to determine the relationship between ITN coverage and the prevalence of malaria parasitemia. Statistical significance was designated at $p \leq 0.05$.

\section{Results}

A total of 504 households were surveyed amongst which 295 (58.5\%) were headed by individuals who had acquired at most primary level education while 58 (11.5\%) were individuals who had attained at least higher education. With respect to the various sites, participants from Ombe were dominated $43(82.7 \%)$ by those who attended at most primary education compared to Muea and Dibanda with a higher education attainment as their highest level of education $61(56.5 \%)$ and $38(50.0 \%)$ respectively $(p<0.0001)$.

Regarding the nature of the houses surveyed 54(88.5\%) of the 61 houses found in Tole were wooden houses followed by Bolifamba with 45(63.4\%) of 71 houses surveyed while majority of houses in Mutenegene 96(70.6) and Dibanda 49(64.5\%) were cement block houses $(p<$ 0.0001). No significant difference was found between number of occupants in a household and the various communities involved ( $\mathrm{p}, 0.125$ ).

A total of 915 ITNs were found within the households surveyed. During inspection it was discovered that 490 (53.6\%) of the nets were torn and the highest number of torn nets was found in Dibanda 99(74.4\%) of 133 net compared to $101(42.1 \%)$ of 140 nets found in Mutengene $(p=0.011)$. The characteristics of respondents are presented on Table 1.

\section{Ownership and usage of ITNs within households in the Mount Cameroon area}

From Table 2 of the 504 households surveyed, 391 (77.6\%) owned at least a net. Within the houses 1564 bed spaces were recorded and 915 ITNs were reported and confirmed giving a coverage of $58.5 \%$ of bed spaces and an average of 1.8 (SD 1.3) ITNs per household. Tole had the least coverage (25.7\% coverage of bed spaces and $52.5 \%$ coverage of households) while Muea had the highest coverage (78.9\% coverage of total bed spaces and $88.9 \%$ coverage of households) $p<0.0001$. A total of 3040 persons were declared in the households with 2459 (80.89\%) belonging to the households with at least one net.

As shown in Table 3, of the 504 households surveyed, $367(94.8 \%)$ had at least one ITN in use while about $88 \%$ of the ITNs in the communities were in use. Tole had the least number of ITNs in use (67.4\%) and Muea significantly higher $(97.5 \%) p<0.0001$. In Muea and Dibanda, all the households that owned ITNs had at least one in use. Out of 391 households with at least one ITN, 303 slept under their ITNs the night before the survey giving an overall usage rate of $77.5 \%$ while 208 had slept under their ITNs for at least the last two nights before survey was conducted thus, an overall rate of 53.7 regular users. Tole had the lowest overall rate of regular ITNs usage of $31.3 \%$ while Dibanda had the highest usage rate of $68.09 \% p<0.0001$.

\section{ITNs that are not in use in the community}

Out of 915 ITNs found in the communities 111(12.13\%) were found folded up or in package and 11(1.2\%) were used for other purposes such as window nets, to partition a room and on toilet doors. Tole had the highest number of ITNs in package (32.61\%) followed by Bolifamba (22.0\%) while Didanda had the least number of ITNs in package (3.0\%) as shown in Fig. 1.

\section{Reason for not sleeping under the ITNthe day before the survey was conducted}

Several reasons were put forth by those who still had ITNs in package and those who did not sleep under their ITNs the previous night before the survey. In general the most frequently reported reasons for not sleeping under the net were "too hot/feel heat in" (33.25\%) and the perception of "no mosquitoes" (33.25\%) as shown on (Fig. 2). With respect to the various study sites, the reasons of not using ITNs was dominated by too hot/feel heat in. It is worth noting that the highest number of people who failed to use their net because of "too hot/feel heat in" was recorded in Ombe (60\%). However in Mutengene the most common reason for not sleeping under net was the perception of no mosquitoes (50\%) (Fig. 3).

\section{Bivariate logistic regression analysis of the association between net usage and possible explanatory factors} With respect to ITN usage at the level of the households it was observed that most of the households (87.6\%) that had torn ITNs used them the night before the survey compared to households that had good ITNs $(\mathrm{OR}=2.11,95 \%$ CI: $(1.16-3.83), \quad p<$ $0.00001)$. It was also observed that ITN usage within households was higher among households with 5 to 9 occupants (OR $=2.41,95 \%$ CI: $1.57-3.69, \quad p=$ $0.0001)$ and those with 10 or more occupants $(\mathrm{OR}=$ 3.15, 95\% CI: $1.53-6.47 p=0.002)$ when compared to households with less than 5 occupants. Furthermore, ITNs usage was lower among individuals living in cement block houses (OR .488, 95\%CI: 0.23-0.89; $p=0$.018) compared to those living in wooden houses as shown on Table 4.

With respect to altitude it was observed that ITNs usage is reduced at low altitude when compared to intermediated altitude $(\mathrm{OR}=0.607,95 \%$ CI: 0 .44$0.85, p=.003)$ while individual factors such as age group, level of education, and gender were not associated to ITN usage. 
Table 1 Characteristics of respondents in the Mount Cameroon area September, 2014

\begin{tabular}{|c|c|c|c|c|c|c|c|c|c|}
\hline \multirow[t]{2}{*}{ Factor } & \multirow[t]{2}{*}{ Category } & \multicolumn{7}{|c|}{ Site N (\%) } & \multirow[b]{2}{*}{$P$ value } \\
\hline & & Total & Tole & Muea & Bolifamba & Dibanda & Mutenegene & Ombe & \\
\hline \multirow[t]{3}{*}{$\begin{array}{l}\text { Level of education of the head of } \\
\text { household }\end{array}$} & $\begin{array}{l}\text { At most } \\
\text { Primary }\end{array}$ & 295 & $\begin{array}{l}38 \\
(62.3)\end{array}$ & $61(56.5)$ & $43(60.6)$ & $38(50.0)$ & $72(52.9)$ & $43(82.7)$ & \multirow[t]{3}{*}{0.001} \\
\hline & Secondary & 151 & $\begin{array}{l}20 \\
(32.8)\end{array}$ & $37(34.3)$ & $23(32.4)$ & $23(30.0)$ & $39(28.7)$ & $9(17.3)$ & \\
\hline & Higher & 58 & $3(4.9)$ & $10(9.3)$ & $5(7.0)$ & $15(19.7)$ & $25(18.4)$ & $0(0.0)$ & \\
\hline \multirow[t]{2}{*}{ Nature of house } & Cement block & 235 & $7(11.5)$ & $45(41.7)$ & $26(36.6)$ & $49(64.5)$ & $96(70.6)$ & $12(23.1)$ & \multirow{2}{*}{$\begin{array}{l}< \\
0.00001\end{array}$} \\
\hline & Wooden house & 269 & $\begin{array}{l}54 \\
(88.5)\end{array}$ & $63(58.3)$ & $45(63.4)$ & $27(35.5)$ & $40(29.4)$ & $40(76.9)$ & \\
\hline \multirow[t]{2}{*}{ Nature of net } & Torn & 490 & $\begin{array}{l}24 \\
(52.2)\end{array}$ & $147(53.1)$ & $76(50.7)$ & $99(74.4)$ & $101(42.1)$ & $43(62.3)$ & \multirow[t]{2}{*}{0.011} \\
\hline & Good & 425 & $\begin{array}{l}22 \\
(47.8)\end{array}$ & $\begin{array}{l}130 \\
(46.93)\end{array}$ & $74(49.33)$ & $\begin{array}{l}34 \\
(25.56)\end{array}$ & $139(57.91)$ & $\begin{array}{l}26 \\
(37.68)\end{array}$ & \\
\hline Number of households surveyed & & 504 & $\begin{array}{l}61 \\
(12.1)\end{array}$ & $108(21.4)$ & $71(14.1)$ & $76(15.1)$ & $136(27.0)$ & $52(10.3)$ & - \\
\hline \multirow[t]{3}{*}{ Number of occupants in a household } & $1-4$ & 167 & $\begin{array}{l}21 \\
(34.4)\end{array}$ & $29(26.9$ & $21(29.6)$ & $30(39.5)$ & $49(36.3)$ & $17(32.7)$ & \multirow[t]{3}{*}{0.125} \\
\hline & $5-9$ & 272 & $\begin{array}{l}38 \\
(62.3)\end{array}$ & 58)53.7) & $40(56.3)$ & $36(47.4)$ & $74(54.8)$ & $26(50.0)$ & \\
\hline & $\geq 10$ & 64 & $2(3.3)$ & $21(19.4)$ & $10(14.1)$ & $10(13.2)$ & $12(8.9)$ & $21(19.4)$ & \\
\hline
\end{tabular}

Multivariate logistic regression analysis of the association between net usage and possible explanatory factors

The Multivariate model was done with five variables that were significantly associated with ITN usage in the bivariate analysis. This revealed that the most determinant factors associated with increased ITN usage were the nature of house and altitude. The odds of ITNs usage was reduced by $38 \%$ among households at low altitude compared to those at intermediate altitude $(\mathrm{OR}=0.613,95 \% \mathrm{CI}: 0.44-0.86, p=.004)$. The nature of the house was also significantly associated with reduced ITN usage, likewise the odds for using ITNs was reduced by $51 \%$ among individuals living in cement block houses when compared to those living in wooden houses $(\mathrm{OR}=0.49,95 \% \mathrm{CI}$ : 0.269-0.885, $P=.018)$. After adjusting for other factors it was also observed that the odd of using ITNs was $87 \%$ higher among individuals with torn nets compared to those with good ITNs, $(\mathrm{OR}=1.87,95 \% \mathrm{CI}$ : 1.133.10, $P=.015)$ as presented on Table 5 .

\section{Relationship between ITN coverage, usage and malaria parasitemia prevalence}

The overall prevalence of malaria parasitemia in the study population was $20.1 \%$. In a binary logistic regression, after adjusting for age group and sex it was observed that the likelihood of having malaria infection was decreased by 32.7 and $57.4 \%$ among irregularly and regular ITNs users respectively, when compared with non-users. However, the likelihood of having malaria infection was only significantly reduced among regular ITNs users $(p=0.036)$ as

Table 2 ITN coverage in the Mount Cameroon Area, September 2016

\begin{tabular}{lllll}
\hline Study Site & Coverage & & \\
\cline { 2 - 5 } & Number of households surveyed $(\mathrm{H})$ & Number of bed spaces reported $(\mathrm{N})$ & $\begin{array}{l}\text { Number of ITNs found } \\
(\mathrm{N} \%)\end{array}$ & $\begin{array}{l}\text { Households with At least one ITNs } \\
(\mathrm{H} \%)\end{array}$ \\
\hline Ombe & 52 & 174 & $69(39.7)$ & $38(73.1)$ \\
Tole & 61 & 179 & $46(25.7)$ & $32(52.5)$ \\
Mutengene & 136 & 406 & $240(59.1)$ & $115(84.6)$ \\
Dibanda & 76 & 246 & $133(54.1)$ & $43(56.6)$ \\
Bolifamba & 71 & 208 & $150(72.1)$ & $63(88.7)$ \\
Muea & 108 & 351 & $277(78.9)$ & $96(88.9)$ \\
Overall & 504 & 1564 & $915(58.5)$ & $387(76.8)$ \\
$P$-value & - & - & $<0.0001$ & $<0.0001$ \\
\hline
\end{tabular}


Table 3 ITN usage in the Mount Cameroon Area, September 2016

\begin{tabular}{|c|c|c|c|c|c|c|}
\hline \multirow[t]{2}{*}{ Study Site } & \multicolumn{6}{|l|}{ ITNs Usage } \\
\hline & $\begin{array}{l}\text { Number of } \\
\text { households } \\
\text { surveyed H }\end{array}$ & $\begin{array}{l}\text { Households with At least } \\
\text { one ITNs }=n(H \%)\end{array}$ & $\begin{array}{l}\text { Number of } \\
\text { ITNs found (N) }\end{array}$ & $\begin{array}{l}\text { Number of } \\
\text { ITNs in use \%) }\end{array}$ & $\begin{array}{l}\text { Households with at least } \\
\text { one ITNs in use }(n \%)\end{array}$ & $\begin{array}{l}\text { Households with } \\
\text { Regular ITN Usage (n \%) }\end{array}$ \\
\hline Ombe & 52 & $38(73.1)$ & 69 & 65 (94.2) & 37 (97.4) & $26(68.4)$ \\
\hline Tole & 61 & $32(52.5)$ & 46 & $31(67.4)$ & 26 (81.3) & 10 (31.3) \\
\hline Mutengene & 136 & $115(84.6)$ & 240 & $196(81.7)$ & $105(91.3)$ & 35 (30.4) \\
\hline Dibanda & 76 & 43 (56.6) & 133 & $129(96.9)$ & $43(100)$ & 32 (681) \\
\hline Bolifamba & 71 & 63 (88.7) & 150 & $117(78.0)$ & $56(88.9)$ & 35 (55.5) \\
\hline Muea & 108 & 96 (88.9) & 277 & $270(97.5)$ & 96 (100) & 70 (72.9) \\
\hline Overall & 504 & $387(76.8)$ & 915 & 808 (88.3) & 367 (94.8) & $208(53.7)$ \\
\hline$P$-value & & $<0.0001$ & - & $<0.0001$ & $<0.0001$ & $<0.0001$ \\
\hline
\end{tabular}

shown on Table 6. From Fig. 4 it was observed that Tole with the least coverage and usage of ITNs (25.7 and 38.35\% respectively) had the highest prevalence of malaria parasitemia while Muea and Bolifamba with the higher coverage (78.9 and $72.1 \%$ respectively) and usage (67.2 and $62.5 \%$ respectively) of ITNs had the least prevalence of malaria parasitemia. In a binary correlation between ITN coverage and the prevalence of malaria parasitemia it was showed that the prevalence of malaria decreases with increase in ITNs coverage $(r=-0.899, p=0.015)$. On the other hand, binary correlation between usage and the prevalence of malaria parasitemia also indicated that the prevalence of malaria decreases with an increase in ITN usage, though not significantly $(r=-0.641, p=0.170)$ as detailed out in Table 7 .

\section{Discussion}

The aim of this study was to determine the coverage of ITNs, usage rate and factors associated to ITN usage among residents of malaria endemic communities within the Mount Cameroon area. The study also examined the effect of ITNs coverage and usage on the prevalence of malaria parasitemia. ITN coverage was expressed in three ways: the number of ITNs per bed space, average number of ITNs per household and the proportion of households with at least one ITN. Ombe and Tole had the least ITNs coverage. This can be explained by the fact that Ombe and Tole are rural communities which never had ITN distribution points during massive distribution campaigns. Thus, during ITNs distribution they

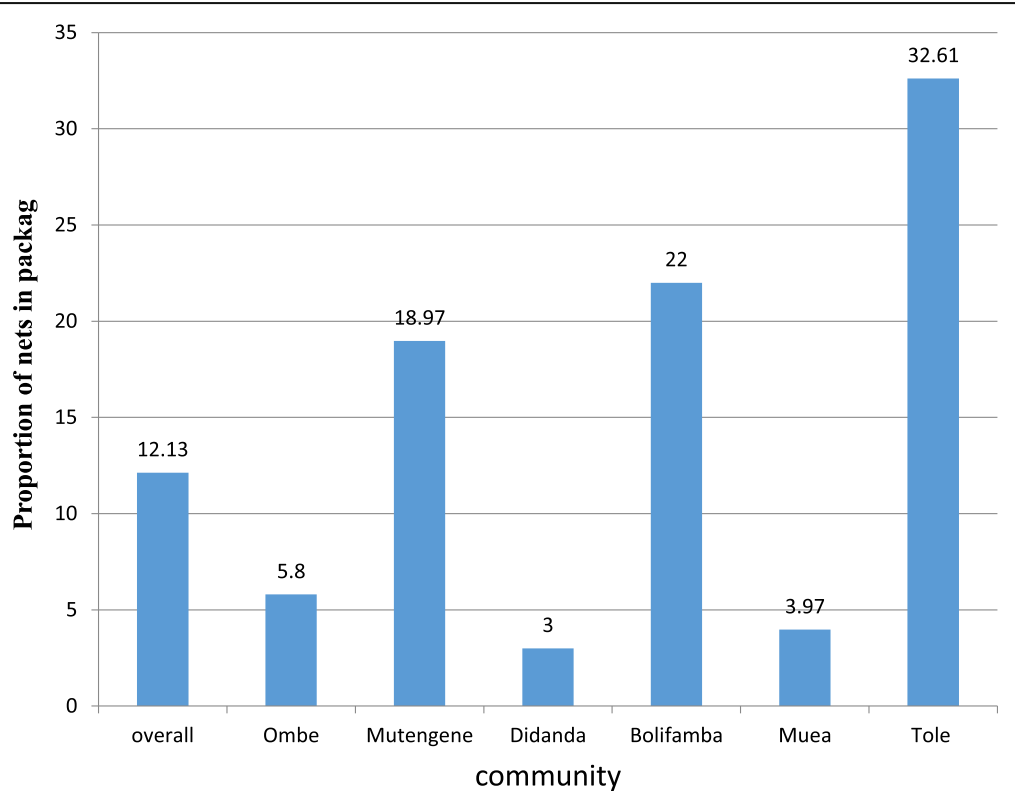

Fig. 1 Proportion of nets that are not in use in the community 


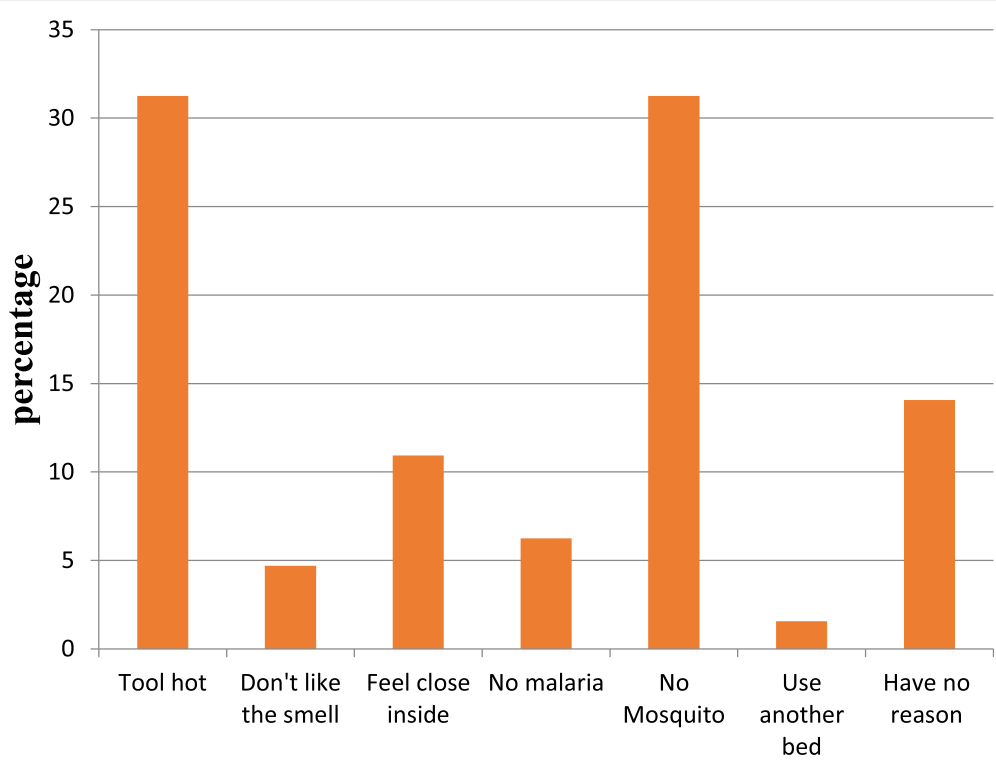

Reason for not using ITNs

Fig. 2 Reasons for not using ITNs within the households

probably did not have the same chance of receiving nets compared to people resident in the semi-urban communities. This observation was in agreement with previous studies [25-28] that demonstrated consistent inequities between urban and rural populations during bed nets distribution campaigns.

The 58.5\% coverage of bed spaces was very low with respect to the Ministry of Public Health's ambition to achieve 100\% coverage of bed spaces in 2015 [29]. Nonetheless, the $77.6 \%$ coverage of households recorded was higher than the 59.7\% reported earlier [3] and 69.3\% [5].
The difference here may be due to the continuous effort of the national malaria control program to foster the use of ITNs.

The proportion of ownership versus regular usage (77.6\% Vs 58.0\%) points to the problem of noncompliance that was earlier shown by other studies in, Kenya, Tanzania Nigeria and in Yaounde, Cameroon [3, 5, 9-11].

Of the total number of ITNs found in the communities, $53.6 \%$ of the ITNs were torn, probably due to the fact that most of the nets were acquired about 3 years ago (during the nationwide distribution campaign) and

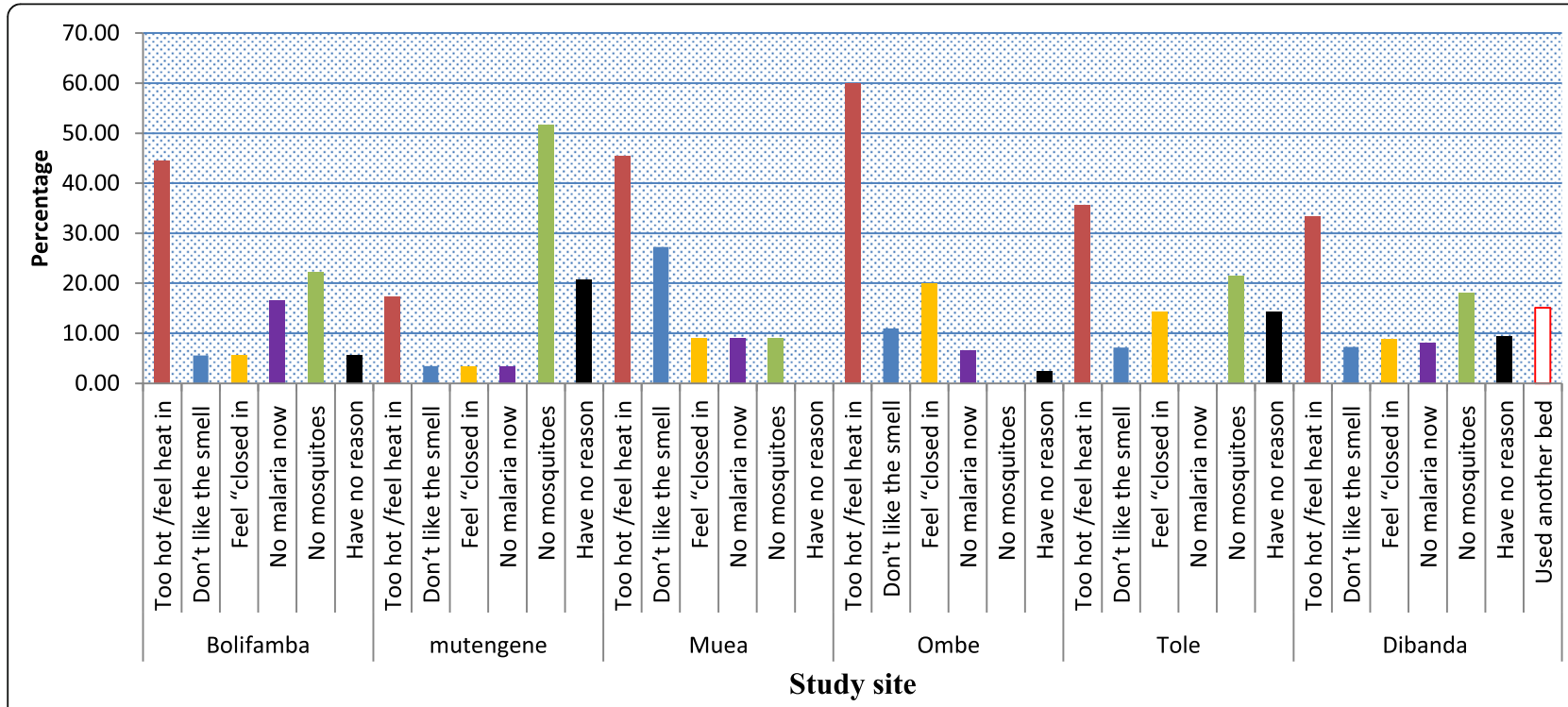

Fig. 3 Community specific reasons for not using ITNs within the households 
Table 4 Bivariate logistic regression analysis of the association between net usage and possible explanatory factors

\begin{tabular}{|c|c|c|c|c|c|}
\hline Factor & Category & Number of participants (n) & Used ITN (n\%) & $\mathrm{OR}(95 \% \mathrm{Cl})$ & P-value \\
\hline \multirow[t]{3}{*}{ Number of house occupants } & $<5$ & 167 & $101(60.5)$ & 1 & \\
\hline & $5-9$ & 272 & $214(78.7)$ & $2.41(1.57-3.69)$ & 0.001 \\
\hline & $\geq 10$ & 64 & $53(82.8)$ & $3.15(1.53-6.47)$ & 0.002 \\
\hline \multirow[t]{3}{*}{ Level of education } & At least Higher & 58 & $17(29.3)$ & 1 & \\
\hline & Secondary & 151 & $42(27.8)$ & $1.070(0.55-2.10)$ & 0.830 \\
\hline & At most Primary & 295 & $76(56.3)$ & $1.11(0.64-2.23)$ & 0.575 \\
\hline \multirow[t]{2}{*}{ Nature of house } & Wooden & 195 & $177(90.8)$ & 1 & 1 \\
\hline & Cement block & 308 & $234(76.2)$ & $.49(0.25-.89)$ & 0.018 \\
\hline \multirow[t]{2}{*}{ Nature of nlet } & Torn & 275 & $241(87.6)$ & $2.11(1.16-3.83)$ & 0.014 \\
\hline & Good & 96 & $74(77.1)$ & 1 & \\
\hline \multirow[t]{2}{*}{ Altitude } & Low & 188 & $61(32.4)$ & $0.607(0.44-0.85)$ & 0.003 \\
\hline & Intermediate & 315 & $147(46.7)$ & 1. & \\
\hline \multirow[t]{2}{*}{ Community status } & Rural & 63() & $36(57.1)$ & $.923(0.44-1.95)$ & 0.834 \\
\hline & Urban & 304 & $213(70.0)$ & 1.0 & \\
\hline \multirow[t]{2}{*}{ Gender } & Male & 1331 & $891(66.9)$ & $0.98(0.73-1.32)$ & 0.885 \\
\hline & Female & 1708 & $1134(66.4)$ & 1 & \\
\hline \multirow[t]{4}{*}{ Age Group (Years) } & $<5$ & 662 & $289(43.7)$ & $1.038(0.72-1.50)$ & 0.841 \\
\hline & $5-9$ & 626 & $254(40.6)$ & $1.178(0.81-1.71)$ & 0.393 \\
\hline & $10-15$ & 407 & $125(30.8)$ & $1.805(1.14-2.86$ & 0.012 \\
\hline & $>15$ & 1340 & $598(44.6)$ & 1 & 1 \\
\hline
\end{tabular}

1 is the reference group

have therefore been in use for long. Furthermore, most of the sensitization talks given to the population are focused more on creating awareness about the benefits of ITNs usage and very little is usually said about its maintenance. The highest number of torn nets found in Dibanda can be explained by the fact that usage was higher in Dibanda coupled to the fact that Dibanda had the least number of nets in package.
Tole had the highest number of nets in package (52.6\%). This may be attributed to ignorance on the part of the population which is dominated by individuals who have attended at most primary level of education. In addition, Tole lacks a fully functional health facility which plays an important role in the sensitization of the population especially during antenatal consultations (ANC).

Table 5 Multivariate logistic regression analysis of the association between net usage and possible explanatory factors

\begin{tabular}{|c|c|c|c|c|c|}
\hline Factor & Category & OR & $95 \% \mathrm{Cl}$ & P-value & $P$-value $p$-value test for trend \\
\hline \multirow[t]{3}{*}{ Number of house occupants } & $<5$ & 1 & & & 0.072 \\
\hline & $5-9$ & 0.99 & $(.32-3.06)$ & .989 & \\
\hline & $\geq 10$ & 0.48 & $(.18-1.29)$ & .149 & \\
\hline \multirow[t]{2}{*}{ Nature of house } & Wooden & 1 & & & 0.016 \\
\hline & Cement block & 0.49 & $0.269-0.885$ & .018 & \\
\hline \multirow[t]{2}{*}{ Nature of net } & Torn & 1.87 & $1.13-3.10$ & 0.015 & 0.00001 \\
\hline & Good & 1 & & & \\
\hline \multirow[t]{2}{*}{ Altitude } & Low & .613 & $.44-.86$ & .004 & 0.003 \\
\hline & Intermediate & 1.0 & & & \\
\hline \multirow[t]{4}{*}{ Age Group (Years) } & $<5$ & 1.01 & $.70-1.46$ & .948 & 0.08 \\
\hline & $5-9$ & 1.145 & $.78-1.67$ & .489 & \\
\hline & $10-15$ & 1.75 & $1.10-2.78$ & .018 & \\
\hline & $>15$ & 1.0 & & & \\
\hline
\end{tabular}


Table 6 Relationship between bed net usage and the prevalence of malaria parasitemia

\begin{tabular}{|c|c|c|c|c|}
\hline Status of ITNs usage & Number individuals enrolled & Number positive (\%) & Adjusted OR & $P$ value \\
\hline Non users & 278 & $65(23.3)$ & 1 & \\
\hline Irregular users & 66 & $13(19.7)$ & $0.673(0.391-1.487)$ & 0.426 \\
\hline Regular users & 466 & $83(17.8)$ & $0.426(0.467-0.972)$ & 0.036 \\
\hline Overall & 800 & $161(20.1)$ & & \\
\hline
\end{tabular}

NB Non users is the control group (1)

Amongst the reasons advanced by the participants for not using their ITNs, 'too hot/feel heat in' and 'No mosquitoes were the most frequent reasons. This finding is consistent with previous reports $[9,11]$. When the reasons for not using ITNs were analyzed per community, $60 \%$ of the participants in Ombe reported that 'hot/feel heat in the net' was the reason why they failed to sleep under the nets even during the rainy reason. A probable reason for this is the fact that Ombe is found at lowest altitude and is therefore, hotter than the other communities. In Mutengene the perception of no mosquitoes was the main reason for not using bed nets. This can be accounted for by the fact that Mutengene had the highest number of cement block houses. Occupants in cement block houses may be misled by the fact that everywhere is sealed which will prevent mosquitoes from entering the house. This finding was further supported by the relationship observed between ITN usage and nature of household.

Previous studies have shown that ITNs usage is associated with level of education, age and gender [3, 30-32]. This study found no association between ITNs usage and these factors. This contradiction may be explained partially by the fact that in the past malaria control strategies gave more attention to vulnerable groups like children below 5 years and pregnant woman. Besides, public health awareness campaign have educated people on the benefits of using ITNs as a tool of malaria prevention. Furthermore, the recent move towards universal coverage which has been strengthened through repeated massive distribution of ITNs must have been minimized these discrepancies.

It was observed that ITN usage increases with an increase in number of occupants per household. This is because net usage depends on the likelihood of the user being sensitized on its benefits. The greater the number of occupants in a household, the more the chances of having someone who can educate the others on the benefits of ITN usage.

A previous study [33] reported that the prevalence of malaria parasitemia decreases with increasing altitude. In contrast, results of this study demonstrated that Tole which is at the highest altitude had the highest prevalence of malaria parasitemia. This discrepancy can be partially explained by the fact that Tole had the lowest coverage of ITNs (only one out of every four bed spaces had a ITN and about five out of every ten households

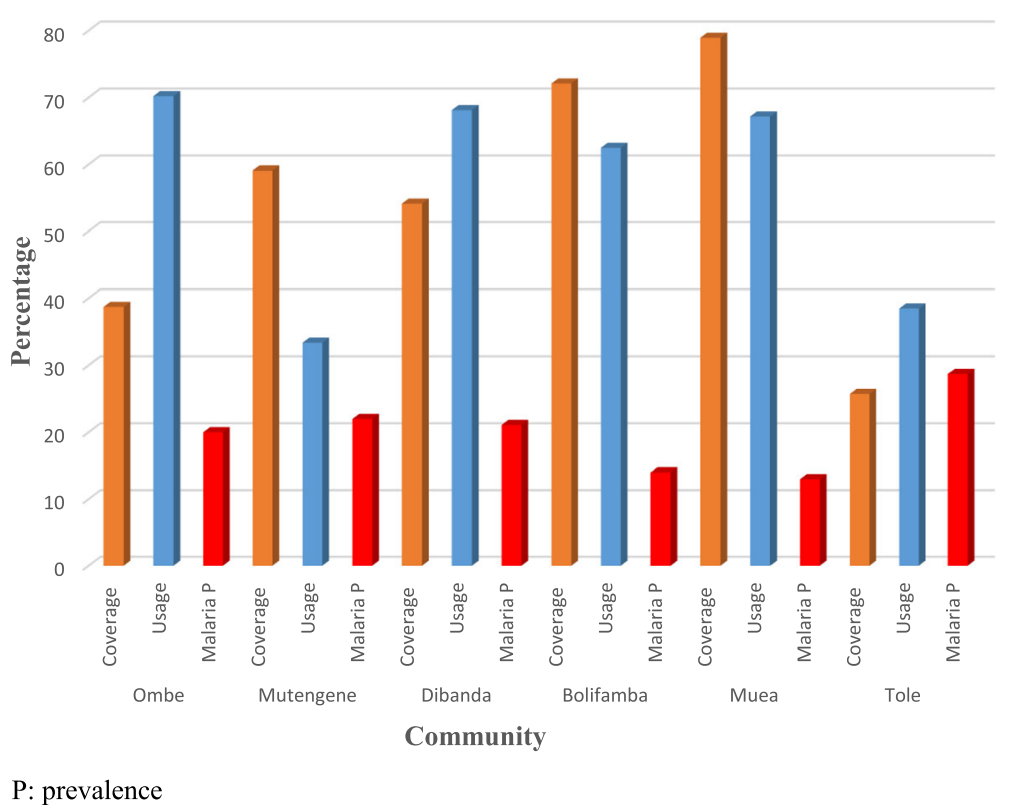

Fig. 4 Percentage of ITNs coverage, usages and malaria prevalence across communities 
Table 7 Correlation matrix of ITN coverage, usage and the prevalence of malaria

\begin{tabular}{lllll}
\hline & & Coverage & Usage & malaria $p$ \\
\hline Coverage & Pearson Correlation & 1 & 0.341 & -0.899 \\
& P, value & - & 0.508 & 0.015 \\
Usage & Pearson Correlation & 0.341 & 1 & -0.641 \\
& P, value & 0.508 & - & 0.170 \\
\multirow{4}{*}{ malaria p } & Pearson Correlation & -0.899 & -0.641 & 1 \\
& P, value & 0.015 & 0.170 & - \\
\hline
\end{tabular}

had at least bed net). This finding was in accordance with another study of [34] which demonstrated that malaria parasitemia prevalence varies with ITNs coverage.

The highest prevalence of malaria parasitemia was recorded among non-ITN users while regular ITN users had the least prevalence of malaria parasitemia. A possible explanation can be the difference in exposure of these individuals to the malaria vectors. Thus, fewer mosquitoes bites means fewer inoculations and therefore, fewer malaria infection episodes. This was in agreement with a previous report [7] which stipulated that in order to achieve the full benefits of bed nets, individuals need to own and use them properly and regularly.

\section{Conclusion}

Despite the efforts made to scale up ITN distribution so that universal coverage can be attained, coverage remains low. ITN usage was affected by the number occupants per household, altitude and the nature of house while 'too hot/feel heat in' and 'No mosquitoes' were the most frequent reasons for not using ITNs. The prevalence of malaria parasitemia was reduced by more than $50 \%$ among regular ITNs users while an while increased in ITN coverage significantly reduces malaria prevalence. It is therefore evident that in order to achieve the full benefits of ITNs as a tool of vector control and as a strategy to cut down the prevalence of malaria parasitemia, coverage needs to be increased and a mechanism put in place to replace torn nets. The entire population should be educated on the benefits of regular usage and maintenance of bed nets.

\section{Additional files}

Additional file 1: Questionnaire develop and used for the study (DOCX $15 \mathrm{~kb})$

Additional file 2: Raw data collected for the e study (SAV $36 \mathrm{~kb}$ )

\section{Abbreviations}

ACTs: Artemisinin-based combination Therapies; ANC: Antenatal Consultations; EIR: Entomological Inoculation Rates; ITNs: Insecticide-treated nets; NMCPN: National Malaria Control Program; WHO: World Health Organisation

\section{Acknowledgments}

We appreciate all participants from the various communities who made this study possible and the Chiefs, Quarter Heads and all community health workers who assisted with this work.

\section{Authors' contributions}

CN conceived, designed and coordinated the study, participated in data analysis and drafted the paper. TOA conceived, designed and participated in data analysis and drafting of the first manuscript. JKA conceived, designed and critically revise the manuscript. ETA participated in data collection, entry and analysis. EAT participated data analysis and interpretation and conducted the literature search. CN participated in designing of the study and revised the manuscript. EAA conceived, designed and supervise the study implementation. All authors read and approved the final manuscript.

\section{Funding}

This study received no external funding, all resources used in the study was provided by the corresponding author.

\section{Availability of data and materials}

All the data collected that supports the findings of this study has been presented in the manuscript. However, the raw data has been made available (Additional file 2).

\section{Ethics approval and consent to participate}

The study protocol was reviewed and approved by the Faculty of Health Sciences Institutional Review Board (IRB) of the University of Buea, Cameroon and written informed consent was obtained from all participants.

\section{Consent for publication}

Not applicable.

\section{Competing interests}

The authors declare that they have no competing interests.

\section{Author details}

${ }^{1}$ Global Research Education and health Foundation Buea, Molyko, P.O. BOX 356, Buea, South West Region, Cameroon. ${ }^{2}$ Department of Biochemistry and Molecular Biology, University of Buea, Buea, Cameroon. ${ }^{3}$ Department of Microbiology and Parasitology, University of Buea, Buea, Cameroon. ${ }^{4}$ Department of Zoology and Animal Physiology, University of Buea, Buea, Cameroon. ${ }^{5}$ Department of Public Health and Hygiene, University of Buea, Buea, Cameroon. ${ }^{6}$ Department of Animal Biology and Physiology, University of Yaounde I, Yaounde, Cameroon. ${ }^{7}$ College of Technology, University of Bamenda, Bamenda, Cameroon.

Received: 11 October 2018 Accepted: 27 August 2019

Published online: 03 September 2019

\section{References}

1. World Health Organisation. World Malaria Report 2016. Available at http:// www.who.int/malaria/publications/world-malaria-report-2016/report .

2. Fombang foundation. The Cameroon malaria research and control report 2008-2011. Younde 2012.

3. Tchinda VHM, Keundo ASA, Zeukeng F, Seumen CT, Leke FGR, Moyou RS. Factors associated to bed net use in Cameroon: a retrospective study in Mfou health district in the Centre region. Med J. 2012;12:112.

4. Sibhatu B, Ayalu R, Haji K. Determinants of ownership and utilization of Insecticide-Treated bed nets for malaria control in eastern Ethiopia. J Trop Med. 2012. https://doi.org/10.1155/2012/23501.

5. Apinjoh TO, Anchang-Kimbi JK, Mugri RN, Tangoh DA, Nyingchu RV, Chi HF, et al. The effect of insecticide treated nets (ITNs) on Plasmodium falciparum infection in rural and SemiUrban communities in the south west region of Cameroon. PLoS One. 2015. https://doi.org/10.1371/journal.pone.0116300.

6. Ngum HN, Veyufambom S. Assessing the effective use of mosquito nets in the prevention of malaria in some parts of Mezam division, northwest region Cameroon. Malar J. 2016. https://doi.org/10.1186/s12936-016-1419.

7. World Health Organisation. Insecticide-treated mosquito nets: a WHO position statement. Geneva 2107 Available at http://www.ivcc.com/sites/ ivcc.mrmdev.co.uk/files/content/itnspospaperfinal.pdf. . 
8. Loha E, Tefera K, Lindtjørn B. Freely distributed bed-net use among Chano mille residents, South Ethiopia: a longitudinal study. Malar J. 2013;12:23.

9. Githinji S, Herbst S, Kistemann T, Noor AM. Mosquito nets in a rural area of western Kenya: ownership, use and quality. Malar J. 2010;9:250.

10. Ruhago GM, Mujinj PGM, Norheim OF. Equity implications of coverage and use of insecticide treated nets distributed for free or with copayment in two districts in Tanzania: a cross-sectional comparative household survey. Int J. 2012;10:29.

11. Patton EY, Kilian A, Dovey S, Eckert E. Can universal insecticide-treated net campaigns achieve equity in coverage and use, the case of northern Nigeria. Malar J. 2012;11:32.

12. World Health Organisation. Factors that affect the success and failure of InsecticideTreated net programs for malaria control in SE Asia and the Western Pacific. Geneva 2011. Available at www.who.int/malaria/ publications/atoz/itn_r62/en.

13. Arogundade ED, Adebayo SB, Anyanti J, Nwokolo E, Ladipo O, Ankomah A, Meremikwu MM. Relationship between care-givers' misconceptions and non-use of ITNs by under-five Nigerian children. Malar J. 2011:10:12.

14. Moiroux N, Boussari O, Dje'nontin A, Damien G, Cottrell G, Henry M-C, Guis $\mathrm{H}$, Corbel V. Dry season determinants of malaria disease and net use in Benin, West Africa. PLoS One. 2012;7:55.

15. Yafi CN, Achidi EA, Anchang-Kimbi JK, Apinjoh TO, Mugri RN, Chi HF, Tata RB, Njumkeng C, Nkock E, Nkuo-Akenji T. Malaria, helminths, co-infection and anaemia in a cohort of children from Mutengene, south western Cameroon. Malar J. 2016. https://doi.org/10.1186/s12936-016-1111-2.

16. Nkuo-Akenji T, Ntonifor NN, Ndukum MB, Abongwa EL, Nkwescheu A, Anong DN, Songmbe M, Boyo MG, Ndamukong KN, Titanji VP. Environmental factors affecting malaria parasite prevalence in rural Bolifamba, south West Cameroon. Africa Journal of Health Science. 2006;13:40-6.

17. Anchang-Kimbi JK, Achidi EA, Nkegoum B, Sverremark-Ekström E, TroyeBlomberg M. Diagnostic comparison of malaria infection in peripheral blood, placental blood and placental biopsies in Cameroonian parturient women. Malar J. 2009:8:126.

18. DeLancey MW and Dike DM. Historical dictionary of the Republic of Cameroon. Lanham, Maryland (3rded). 2000.

19. Bigoga JD, Manga L, Titanji VPK, Coetzee M, Leke RGF. Malaria vectors and transmission dynamics in coastal South-Western Cameroon. Malar J. 2007;6:5.

20. Achidi EA, Apinjoh TO, Mbunwe E, Besingi R, Yafi CN, Awah NC, Ajua A, Anchang JK. Febrile status, malaria parasitaemia and gastrointestinal helminthiasis in school children resident at different altitudes. Ann Trop Med Parasitol. 2008;102:103-18.

21. Wanji S, Tanke T, Sali NA, Ajonina C, Tendongfor N, Didier F. Malaria transmission in the Mount Cameroon region. Tropical Med Int Health. 2003;7:643-9.

22. Wanji S, Kengne-Ouafo AJ, Eyong EE, Kimbi HK, Tendongfor N, NdamukongNyanga JL, Nana-Djeunga HC, Bourguinat C, Sofeu-Feugaing DD, Charvet CL. Genetic diversity of Plasmodium falciparum Merozoite surface Protein-1 block 2 in sites of contrasting altitudes and malaria Endemicities in the Mount Cameroon region. Am J Trop Med Hyg. 2012;86:764-74.

23. Cheesbrough M. District laboratory practice in tropical countries part Cambridge low price editions (2nd ed). Cambridge University press. 2010; 239-258.

24. Watson, Jeff. How to Determine a Sample Size: Tipsheet \#60, University Park, PA: Penn State Cooperative Extension 2001

25. Sexton AR. Best practices for an insecticide-treated bed net distribution programme in sub-Saharan eastern Africa. Malar J. 2011;10:157.

26. Evangeline TO, Kelechi N. Usage, sustainability and the local population's perceived effectiveness of insecticide-treated bed nets in the control of malaria in old Umuahia district of Abia state, Nigeria. Africa Journal of Apply Zoology, and Environ Biology. 2008:10:40-9.

27. Sena LD, Deressa WA, Ali AA. Predictors of long-lasting insecticide-treated bednet ownership and utilization: evidence from community-based crosssectional comparative study, Southwest Ethiopia. Malar J 2013; doi: https:// doi.org/10.1186/1475-2875-12-406 PMID:24206749.

28. Temu EA, Coleman M, Abilio AP, Keinschmidt I. High prevalence of malaria in Zambeja Mozambique: the protective effect of IRS versus increased isks due to pigkeeping and house construction. PLoS One 2012; dointtps//doiorg/10.1371/joumal.pone.0031409 PMID22363640.

29. National Malaria control Programme. National strategic plan for the fight against malaria 2011-2015, Cameroon; 2010.

30. Pettifor A, Taylor E, Nku D, Duvall S, Tabala M, Meshnick T, Behets FN, et al. Bed net ownership, use and perceptions among women seeking antenatal care in Kinshasa, Democratic Republic of the Congo (DRC): opportunities for improved maternal and child health. BMC Public Health. 2008. https://doi. org/10.1186/1471-2458-8-331.
31. Ndjinga JK, Minakawa N. The importance of education to increase the use of bed nets in villages outside of Kinshasa, Democratic Republic of the Congo. Malar J. 2010. https://doi.org/10.1186/1475-2875-9-279.

32. Graves MP, Ngondi MJ, Hwang J, Getachew A, Gebre T, Mosher WA, Patterson EA, Shargie BE, Tadesse Z, Wolkon A, Reithinger R, Emerson MP, Jro RF. Factors associated with mosquito net use by individuals in households owning nets in Ethiopia. Malar J. 2010;10:354.

33. Kimbi HK, Sumbele IN, Malaika N, Anchang-Kimbi JK, Lum E, Nana Y, Ndip LM, Njom H, Lehman LG. Malaria and haematologic parameters of pupils at different altitudes along the slope of Mount Cameroon: a cross-sectional study. Malar J. 2013;12:193.

34. Eisele TP, Steketee RW. African Malaria Control Programs Deliver ITNs and Achieve What the Clinical Trials Predicted. PLoS Med. 2011;8(9):e1001088. https://doi.org/10.1371/journal.pmed.1001088.

\section{Publisher's Note}

Springer Nature remains neutral with regard to jurisdictional claims in published maps and institutional affiliations.
Ready to submit your research? Choose BMC and benefit from:

- fast, convenient online submission

- thorough peer review by experienced researchers in your field

- rapid publication on acceptance

- support for research data, including large and complex data types

- gold Open Access which fosters wider collaboration and increased citations

- maximum visibility for your research: over $100 \mathrm{M}$ website views per year

At BMC, research is always in progress.

Learn more biomedcentral.com/submissions 